\title{
Identification of Mathematical Difficulties among Grade 3 Children
}

\author{
Maphetla M Machaba \\ University of South Africa (Unisa), Department of Early Childhood development, \\ P.O box 393.Muckleuneck 0003 \\ machabmm@unisa.ac.za
}

\section{Doi:10.5901/mjss.2014.v5n20p1590}

\begin{abstract}
The importance of Mathematics is documented in the curriculum as a major concern in grade 12 which is the exit point of General Education Teaching (GET) band. It is important that children acquire the necessary mathematics skills that will serve as foundation for later learning. It is also the South African government's policy that all children should be taught Mathematics because as it is an important and necessary life skill that cannot be done without. However many teachers are still finding it difficult to teach children to solve mathematical problems. Mathematics performance is a universal outcry in South Africa. Children as early as Foundation Phase are unable to solve mathematical difficulties. In her analysis Naledi Pandor noted in that only $35 \%$ of children in South Africa can read, write and count.
\end{abstract}

Keywords: mathematics, teachers', children, Foundation Phase, mathematical difficulties

\section{Introduction}

There has been a growing recognition of the importance of the early years for the acquisition of mathematical skills in South Africa. The realisation that a strong foundation is needed if children are to be successful in learning mathematics at higher grades prompted the Department of Basic Education (DBE) to conduct systematic evaluations in mathematic competency at primary schools. Although the poor outcome of the Annual Mathematics Assessment (DBE 2010) was symptomatic of dissatisfactory performance levels in the Foundation Phase, research at this level remains scant indicated good mathematical skills later in the school in numerous studies (Department of Basic Education, January 4 (2012:3)

Numerous studies in mathematics (Fricke, Horak, and Meyer 2008; Le Roux 2008; Mbithi 2010; Themane, Monyeki, Nthangeni, Kemper and Twisk 2003) have been conducted in South Africa but the focus has always been on secondary schools. Often the investigations concentrated on classroom variables such as teaching resources and text books that could influence performance but not on teacher attributes that could impact negatively on successful learning. The contention is that the cumulative effect of this oversight can compound into serious mathematics learning problems at higher grades and needs to be addressed early in learner's schooling. It is also important to pay attention to specific difficulties experienced in teaching or learning mathematics in order to propose effective solutions to the problems.

This study emanates from the recognition of problems in the teaching and learning of mathematics in Grade 3 classes of some schools at disadvantaged areas of the Tshwane South District. The particular problem noted is learner's inability to perform basic operations in mathematics. They lack the ability to perform computations such as additions, subtractions, multiplication and division. The concern is if the problems are not addressed in the Foundation Phase it might be too late to deal with them in the higher school grades. In fact it is known that the performance in mathematics at Grade 12 is poor as seen from the TIMMS results (DBE 20).

The aim of this article is to shed light on the approaches teachers use when teaching computations in mathematics. Therefore this study aimed at establishing other difficulties teachers experience when teaching mathematics computations. The case study was chosen as a research design for this study. Creswell (2010:75) and MacMillan \& Schumacher (2010:20) states that a case study describes the procedures for conducting the study , including when from whom, and under what conditions the data will be obtained. In other words, the research design indicates the general plan: how the research is set up, what happens to the subject, and what methods of data collection are used. Research techniques such as observations, interviews and document analysis were used to collect data in answering the research questions. 


\section{Literature Review}

Mathematics underperformance has become a concern. This is evidenced by the report of the former Minister of Education Naledi Pandor. She stated that only 35\% of children in South Africa could read, write and count The Star (November 2008:6).

According to the Global Competitiveness Survey of the World Economic Forum out of 131 surveyed countries, South Africa was ranked 128 for the quality of its mathematics and science education (Pottinger2008:81). Between 1998 and 2005, education in South Africa improved quantitatively but not qualitatively in comparison with other developing countries (Pottinger 2008:134). As from 1998, the number of children in South African schools has increased but not the output as indicated by the Grade 12 results. If children experience challenges in mathematics in the Foundation Phase, they might experience serious problems in Grade 12 later.

The trends in the International Mathematics \& Science study in 2003, showed that South Africa was at the bottom of the pile of 46 participating countries. It was even lower than Ghana, Saudi Arabia and Botswana to mention but a few (Pottinger 2008:138). According to Reddy (2003:17), South African children achieved significantly poorer results in mathematics than all other participating countries, including Morocco and Tunisia, and will be on average older than all other children.

The analysis in the Star (29 June 2011:6) highlighted that all South African children in the nine provinces, estimated at 5 million, wrote a common paper in mathematics and only $17 \%$ managed to score above $50 \%$.

The problem of poor mathematics performance is not only experienced in South Africa, it is universal (Reddy, 2003:17). In an attempt to address this problem in Australia, Van Kraayenoord and Elkins (1998:370-371) and Brown, Askew, Baker, Denvir \& Millet (1998:375) identified certain factors that contribute to poor mathematics performance, namely: teaching method (whole class teaching); failure to use knowledge associated with mathematics; language; lack of flexibility; beliefs; and quality of educator-child interaction. Galton and Simon (Eds) (1980), Good, Grouws \& Ebermeier (1983) and Brophy and Good (1986) also noted that poor performance in mathematics has always been associated with whole class teaching.

The view of this researcher is in agreement with the above-mentioned authors. That when teaching the whole class at the same time, children do not learn in the same way. Children who learn fast may benefit, whereas children who do not catch on quickly will be disadvantaged. Good and Grouws (1980), Erbermeier (1983), and Brophy and Good (1986) argue that in individual cases, particularly poor performance in mathematics has also been associated with whole class teaching. For example, when the teacher uses the whole class teaching method he/she may not be able to interact with all the children at the same time. In such cases, problems experienced by some children are not promptly detected and remedied.

\subsection{Various misconceptions about mathematics teaching}

Schunk (2004:412) assert that the content area of mathematics is a fertile area of cognitive and constructive research. Schunk (2004:412) add that topics that have been explored include how children construct mathematical knowledge, how experts and novices differ and which methods are most effective. Schunk (2004:414) also agree that children and adults often construct procedures to solve numerical/mathematical problems; however, the errors are not random but rather, systematic mistakes. Systematic mistakes reflect the constructivist assumptions that children form procedures based on their interpretation of experiences. For example, a common mistake in subtraction is to subtract the smaller number from the bigger number in each column, regardless of direction, as follows:
$65-29=44$
$571-298=327$

Systematic mistakes develop when the children encounter new problems and incorrectly generalise productions, especially when they do not know what to do. They modify the rules to fit the new problem Schunk, 2004:414). Brown and Burton (1978) also leave a gap on how teachers teach mathematics. This is a teacher challenge in teaching mathematics and is precisely what the researcher in this study wishes to investigate.

\subsection{Language issues in the teaching of mathematics}

According to Naude, Pretorius and Vandeyar (2002:293-294), many Grade 1 children enter South African schools having various academic and learning difficulties that might occur a result of limited language proficiency. A child with limited language proficiency may continue to learn and understand at a slower rate. This explains why Grade 3 children who receive tuition through a language other than their own find it difficult to understand numerical concepts for they also 
struggle to master the medium of instruction itself because language and thought are interwoven. Limited language proficiency leads to learning difficulties. A child has to be competent in expressive and receptive languages in order to understand and carry out academic tasks including mathematics (Naude et al., 2002:294). Children should also be able to commit what they learn to memory and be able to reproduce it when needed. It goes without saying that lack of language proficiency would be an impediment for children at Foundation Phase. Thus, teachers need to be patient in teaching concepts such as minus, divide, etcetera.

Mercer, 2006:508 argues that the tendency of mathematics educators and policy makers to emphasise the distinction between the subject language of mathematics and more informal talk can hinder the process of inducting children into mathematics practices.

(Mercer, 2006:507) argue that group activities offer valuable opportunities for children to construct solutions for themselves through talk which would not be found in whole class teaching. This method encourages children to participate actively in finding solutions to problems while at the same time using language to communicate. In so doing, children are able to understand better and view mathematics exercises as everyday problems rather than something only related to the school environment and a special language — mathematics jargon.

Vygotsky (1978) stresses the significance of language as a psychological and cultural tool (Mercer, 2006:508). He further argues that the social involvement in problem- solving activities constituted an important factor for individual development (Mercer, 2006:508). He charges that intermental (social) activity, mediated through language, can promote intramental (individual) intellectual development. By using language and examples with which the child can associate and those that stem from his immediate environment, will engender better understanding enable the child to relate the process in his own words. The children' capacity will also be stimulated.

There are two ways of interaction through which the spoken language can be related to the learning of mathematics in schools. The first is teacher-led interaction with children -the teacher guides the children in their development and understanding, which can be important in the children' induction into discourses, associated with the particular knowledge domains. This is the concept of dialogue teaching propounded by Alexander (2000). "It concerns more subtle aspects of interaction such as the extent to which teachers elicit children' own ideas about the work they are engaged in, make clear to them to discuss errors and misunderstandings and engage them in extended sequences of dialogue about such matters" (Mercer, 2006:509). "Dialogic" strategies, according to Mercer (2006:510), achieved better learning outcomes.

Alexander (2004:32) suggests that dialogic teaching is a method that employs the power of talk to encourage and expand the children' thoughts and advance their learning and understanding. It involves both the teacher and the children, and relates to teaching across the curriculum. It is an approach that is grounded in the principles of collectively, reciprocity, cognition and observation. Dialogical teaching, therefore, requires children to be actively engaged in doing as well as talking (discussing/explaining) what the lesson is about. This approach as such, is good in the teaching of mathematics where children have to handle concrete objects and explain what they see and in tandem also learn the concepts. Dialogic teaching is characterised by certain features of classroom interaction, such as:

- questions are structured so as to provoke thoughtful answers.

- answers provoke further questions and are seen as the building blocks of dialogue rather than its terminal point.

- individual teacher-child and child-child exchanges are chained into coherent lines of enquiry rather than left stranded and disconnected. In this manner, the children experience the learning process as cooperative activity.

The second context of interaction in which spoken language can be related to the learning of mathematics in schools is that of peer group interaction. By working in pairs or groups, children become involved in interactions that are more "symmetrical" than those of teacher-pupil discourse and have different kinds of opportunities for developing reasoned arguments and describing events (Mercer, 2006:510). The child does not only learn mathematics, but also social interaction.

Teachers can help children to gain relevant knowledge of numerical procedures, terms, concepts and operations. They can also help children to learn how to use language to work effectively and to jointly enquire, reason, consider information, share and negotiate ideas and to make joint decisions. This kind of guidance is not usually offered (Mercer, 2006:510). According to Vaidya (2008:717), some children suffer from dyscalculia. This is characterised by a poor understanding of the number concept and the number system characteristic of their age group. Such children experience difficulties counting, learning abstract concepts of time, direction learning, and recalling facts, sequence of past and future events, and giving and receiving change. They also fail to use rules and procedures to build on known facts. For instance, they may know that $3+5=8$, but would fail to deduce that $5+3=8$. Such children are generally said to have difficulties to 
mathematics learning (see Appendix Y). Without identification and remediation, these children would not be able to be numerically functional.

Mathematics is a "second language" and should be taught as such. It constitutes formal learning of concepts that have hitherto not been frequently used and known to many of the children. Thus they would also seem to be learning a different language to the one they use at home. The conceptual aspects of mathematics learning are connected to the language. It is exclusively bound to the symbolic representation of ideas. Most of the difficulties seen in mathematics result from underdevelopment of the language of mathematics (Sharma, 1989). Teaching of the linguistic elements of mathematics language is sorely neglected. The syntax, terminology, and the translation from English to mathematics language, and from mathematics language to English must be directly and deliberately taught. Consequently, mathematics language can pose challenges for children. For a teacher to get through to her children, she should have an understanding of the "mathematics language". An added problem is that certain mathematics terms such as "hypotenuse" are not found in everyday conversations

\subsection{Teacher challenges in the teaching of mathematics}

South Africa, like other African countries, suffers from a common crisis in teacher supply (Teacher Education Programme Consortium, 2007:9). The problem lies not only in numbers but in specific categories of teachers entering the profession (Metcalfe, 2006:326). She further argued that of newly qualified teachers, $80 \%$ are white, of which $66 \%$ are white women (Metcalfe, 2006:326). Given the demography of the country and the need for mother tongue instruction at the Foundation Phase level, undoubtedly this implies that black Foundation Phase schools and rural schools are bound to suffer a lack of teachers or would be staffed with under-qualified teachers. Since most of the teachers in teacher training stem from the white community, there will be a shortage of black teachers, especially in black rural schools. Black township schools will also be affected by a shortage of teachers since white teachers are afraid of teaching in the townships. Those who are prepared to go to the townships do not know the African languages, which are the languages of instruction in the Foundation Phase, and therefore cannot be of assistance in that regard. This then, exacerbates the already dire situation and increases difficulties to learning and teaching. It becomes even more catastrophic with regard to the teaching and learning of mathematics. Mathematics teaching poses a challenge to teachers as they consider the principles mentioned below.

Carruthers and Worthington (2006:74) argue that many studies of young children' early writing development suggests some ways in which teachers support the growth of understanding. Ginsburg (1977:119) lists three principles of written symbolism in mathematics:

- Children' understanding of written symbolism generally lags behind their informal mathematics, for example, the child heard the number 5 but does not know how it is written.

- Children interpret written symbolism in terms of what they already know.

- Good teaching attempts to foster connections between the child's informal knowledge and the abstract and arbitrary system of symbolism. Hiebert (1984:501) adds that supporting children' early writing development is problematic for some teachers and it appears that introducing the abstract symbolism of mathematics is more so. It is important that the teaching of mathematics is environment based. It is difficult for children to talk about and test out abstract relationships using words alone (Van de Walle, 2004:30).

Teachers have to use objects from the child's own environment when teaching concepts in mathematics. It would be easy for children to understand the concept "two" if they can first associate it with objects with which the child is familiar, for example, that Lethabo has 16 counters and Mpho also 27 counters, and that Lethabo and Mpho's counters amount to 43 (added together). Therefore, the numeral/concept two is not arbitrarily symbolic or imaginary to the child but can be associated with tangible objects like counters. The concepts "add" also becomes clear in the process.

It is important that the teaching of mathematics is environment based. For example, children would understand much better if taught mathematics by using objects from their own environment, for example, bottle tops for counting, or shoes and ice cream sticks. Willis (1998) supports the view that mathematics is more likely to improve if taught in the context in which it occurs. For example, the teacher has 23 sweets of which she gives Maselaelo 7 sweets - how many sweets are left? Indeed, teaching children mathematics using numerical concepts and the application thereof, using problems derived from their own milieu, would make it far easier for them to understand and to relate the subject to their environment. This would motivate children to want to find solutions to problems, as this would be viewed as solving their environmental problems. Numerical concepts would also become easy to follow. For example, from the given example:

$23-7=16$

Children would be able to see and understand how they arrived at the answer. 
Language also plays a vital role. Children should also develop the ability to use the language - listen, speak, question, explain and discuss. It is important that the language used in the teaching of mathematics should be understandable and be pitched at the level of the child. The child would then not only understand mathematics but enjoy it as well. In this way, mathematics difficulties would be eradicated or reduced at an early age in the children' life.

\section{Research Methodology}

The qualitative approach was used in this study to explore the views of grade three teachers regarding the approaches they use in teaching and learning of mathematics computation. We opted for this approach as it allows researchers to gain insight into the inner experience of participants, to determine how meanings are formed through culture, and to discover rather than test variables (White, 2005:81; Corbin \& Strauss, 2008:12). To collect data we used semi- structured interview as it helped to explain in detail what approaches teachers use when they teach computations in mathematics. For the purpose of this paper, we interviewed and observed five teachers from five different schools. The interviews were held during school time and lasted approximately 1-1/1/2 minutes. We conducted individual face-to-face interviews and did the observations with all the five teachers.

\section{Findings and Discussions}

Teachers are using various methods to identify children who experience mathematics problems, but these are not standardised.

The DBE should train teachers to be able to identify such children, based on agreed strategies which would make identification uniform in all schools, and remediation which should follow a standard pattern too.

Teachers who participated in this study among others claimed that they could identify such children when they fail to do well in response to questions in class. As such they did not look into all the reasons leading to failure to respond positively to questions or activities. These teachers themselves are not trained to identify children who experience difficulties (in mathematics) and as such provide a variety of reasons for children's difficulties. Consequently even children who do not experience difficulties might be wrongfully identified as such.

Once these children are identified, remediation should take place promptly by their being enrolled in the proposed programme. In it, the children are to remain until they have mastered the programme or overcome their barriers before they exit the programme and are replaced by new entrants.

\section{References}

Alexander, P. (2004). Towards dialogic teaching. Rethinking classroom tasks (Cambridge Dialogs).

Alexander, R.J. (2000) Policy and Practice in Primary Education: local initiative, national agenda, London: Routledge.

Brown, M., Askew, M., Baker, D., Denvir, H., Millet, A. (1998) Is the National Numeracy Strategy research based? British Journal of Educational Studies, 46 (4), 362-385.

Brown, J.S., \& Burton, R.R. (1978).Diagnostic programme for procedural bugs in basic mathematical skills. Cognitive Science, 4 , 379 426.

Carruthers, E., \& Worthington, M. (2006). Children's Mathematics: Making Marks, Making Meaning. (2nd Ed.) London: Paul Chapman Publishing.

Creswell, J.W. (2010). Qualitative inquiry and research design: choosing among five traditions. Thousand Oaks: Sage.

Copley, J. (Editor). (1999). Mathematics in early years. Reston, VA: National Council of Teachers of Mathematics

Department of Basic Education, January 4 (2012). Big decline in numbers of matric maths passes - Equal Education.

Fricke, E. Horak, L. Meyer, N. Van Lingen. (2008) Lessons from a Mathematics and Science Intervention Programme in Tshwane township schools. South African Journal of Higher Education Vol. 2264 - 77.

Galton, M. \& Simon, B. (eds.) (1980). Progress and performance in the Primary classroom. London: Routledge.

Ginsburg, H. (1977) Children's Arithmetic: the learning process. New York N Y: D.

Good, T.L., Grouws, D.A., \& Ebermeier, H. (1983). Active Mathematics Teaching New York: Longman.

Margolinas, C., Coulange, L., \& Bessot, A. (2005). What can the teacher learn in the classroom? Educational Studies in Mathematics 59 , 205-234.

McMillan, J.H., \& Schumacher, S. (2010). Research in Education. (Evidence Based Inquiry) $7^{\text {th }}$ Ed. United States of America: Library of Congress Cataloguing in Publication Data.

Mercer, N. (2006). Teaching children how to use language to solve Maths problems. Vol. 20, No.6, 2006.

Naude, H., Pretorius, E. \& Vandeyar, S. Teacher professionalism-An innovative Programme for teaching Mathematics to Foundation level children with limited language proficiency. Early childhood development and care. Vol. 173(2-3), 293-315. 
Pottinger, B. (1988).The imperial presidency: P.W. Botha the first ten years, Johannesburg: Southern Book Publishers.

Reddy, V with contribution from Anil K., Diedericks G., \& Winnaar L. (2003). Mathematics and science achievements at South African Schools in TIMMS. Cape Town South Africa: HSRC Press.

Schunk, D.H. (2004). Learning Theories. $4^{\text {th }}$ Ed. United States of America: Library of Congress Cataloguing in Publication Data.

Sharma, Mahesh 1989. How Children Learn Mathematics: Professor Mahesh Sharma, in interview with Bill Domoney. London, England: Oxford Polytechnic, School of Education. 90 min. Educational Methods Unit. Video cassette.

Shulman, L. S. (1986). Those who understand: knowledge growth in teaching, Educational Researcher, 15 (2), 4-14.

Themane, M.J., Monyeki, K.D., Nthangeni, M.E., Kemper, H.C.G. \& Twisk, J.W.R. (2003). The relationship between health (malnutrition) and educational achievements (Maths and English) in the rural children of South Africa. International Journal of Educational Development 23 (2003), 637-643.

The Star November 2008:6.

Vaidya, S. R. (2008). Understanding Dyscalculia for teaching. 718/Education Vol. 124 No.4.

Van Kraayenoord, C.E., \& Elkins, J. (2004).Learning Difficulties in Numeracy in Australia. Journal of Learning Disabilities. Vol.37. No.1.January/February 2004, pp 32- 41.

Vygotsky, L. (1978). Mind in society. Cambridge: Harvard University Press.

Willis, S. (1998). Which numeracy? Unicorn, 24(2), 32-42. 